\title{
Experiment and Application of Market-Based Control for Engineering Structures
}

\author{
Gang Li, ${ }^{1,2}$ Wen Wang, ${ }^{1}$ and Hong-Nan $\mathrm{Li}^{1}$ \\ ${ }^{1}$ Faculty of Infrastructure Engineering, Dalian University of Technology, Dalian 116023, China \\ ${ }^{2}$ Faculty of Infrastructure Engineering, Dalian University of Technology, Institute of Earthquake Engineering, 2 Linggong Road, \\ Dalian, Liaoning 116024, China
}

Correspondence should be addressed to Gang Li; gli@dlut.edu.cn

Received 5 September 2013; Accepted 24 October 2013

Academic Editor: Delfim Soares Jr.

Copyright (C) 2013 Gang Li et al. This is an open access article distributed under the Creative Commons Attribution License, which permits unrestricted use, distribution, and reproduction in any medium, provided the original work is properly cited.

\begin{abstract}
An experimental study on the vibration control of a single-degree-of-freedom model is carried out to verify market-based control (MBC) strategy effect. Results show that the MBC strategy can reduce both displacement and acceleration responses. Additionally, the MBC strategy is applied to a long-span bridge considering the travelling wave effect. Numerical simulations indicate that the displacement and acceleration responses of the long-span bridge with the travelling wave effect are smaller than those without, and the larger the velocity of travelling wave is, the better the control effect of MBC is. Based on the MBC theory and multimarketbased control (MMBC) presented here it is further applied to a large-space structure considering multiple dimensional features of structural model and ground motions. It is concluded that the MMBC strategy reduces the displacement response of the large-space structure, especially on vertical displacements, but has limited control effects on accelerations.
\end{abstract}

\section{Introduction}

The concept of structural control in civil engineering was first proposed in 1970s [1]. Since then, this technology has been developed greatly. According to the energy source (external or internal), structural control systems can be classified as passive, active, semiactive, or mixed control strategies. For active and semiactive control techniques, the control force is often determined by the control laws. Some typical control laws, that is, linear quadratic regulator (LQR), modal control, smart control, $\mathrm{H}_{2}$ and $\mathrm{H} \infty$, and so forth, have become hot research topics rapidly in recent years [2-5] For general structures, these control laws usually use a central computer responsible for the control of the entire system, but they exhibit limitation for large complex structures due to numerous degrees of freedom of the large complex structure. The market-based control (MBC) as a special control theory introduces the price mechanism of free market economy into the field of structural control in civil engineering. The MBC is developed based on an analogy between the relations of control force-energy sources and those of supply-demand in the market economy. The optimal problem of control force from actuator is transformed to that of allocation resources in the market.

The MBC concept was proposed by Clearwater [6]. It was applied to solve the optimal decentralized control problem of complex dynamic systems, allocate and coordinate the actions of different mechatronic systems, and develop a multi-agent system for realizing the traffic intelligent control [7-9]. In addition, some prior research works about MBC used in various fields were carried out, such as the telecommunication, mechanism, and mission plan [10-12]. Application of the MBC in civil engineering to reduce the structural response under environmental loads has been carried out after the twenty first century [13-17].

However, previous researches mainly focused on ordinary structures, and few emphasized on applications of MBC in long-span and large-space structures. There are still existing problems in applications for these kinds of structures, such as travelling wave effect and multiple dimensions of 
ground motion. The structural control technology in longspan structure have drawn many researchers' attention [1821]. Because an earthquake excitation consists of superposition of a large number of waves carrying different characteristics, the different positions along a long-span structure are generally with different motions. Bridges as typical longspan structures; their control techniques considering multisupport and travelling seismic wave effects have been carried out by various researchers $[22,23]$. These research results showed that control effect had an obvious distinction between uniform ground motion and differential ground motions. Large-space structures generally have thousands of degrees of freedoms and outstanding spatial characteristics; hence, multiple dimensional features, such as the spatial model and inputted ground motions, should be taken into account together. Additionally, theoretical researches have verified that the MBC is an effective control strategy, but experiments with the approach for model or actual structure have not been reported till now. Based on the above reason, a model test is carried out to validate the effectiveness of $\mathrm{MBC}$ in this paper, and the MBC strategy is applied to a long-span bridge considering the travelling wave effect and to a large-space structure considering multiple dimensional ground motion inputs, respectively.

\section{Fundamental and Experiment}

2.1. Basic Theory. The main objective of this study is to solve problems in structural control by the usage of MBC. In the $\mathrm{MBC}$, power sources and controlled devices in a control system are abstracted to sellers and buyers in a free market. The relationship between the energy demand and supply in a control system corresponds to the supply-demand relation in the free market. The supply-demand relation is influenced by the equilibrium price, and the equilibrium price is certainly affected by the supply-demand relation in return. Take a virtual free market and single-degree-offreedom system as an illustration to show the application of the MBC in structural control area.

The governing equation of motion for a SDOF system with controller can be expressed as

$$
m \ddot{x}(t)+c \dot{x}(t)+k x(t)=-F(t)+U(t),
$$

where $x(t), \dot{x}(t)$, and $\ddot{x}(t)$ represent the displacement, velocity, and acceleration of the SDOF system, respectively; $m$ and $k$ are the system mass and stiffness, respectively; $c$ denotes the viscous damping coefficient; $U(t)$ is the controlling force from the actuator; $F(t)$ is the environmental load.

The demand function $J_{D}$ is determined by its energy consumption $Q_{D}$, energy price $p$, and responses of the dynamic system $Y(t)$; the sellers' supply function $J_{S}$ is determined by its own original energy $Q_{S}$ and energy price $p$. Buyers and sellers both pursue their maximum interests at any time. This process has to be restricted by commodity quantities $Q_{\max }$ and virtual wealth $W_{\max }$. The relation is shown as follows:

$$
\begin{aligned}
& \max J_{S}\left(Q_{S}, p\right) \quad Q_{S} \leq Q_{\max }, \\
& \max J_{D}\left(Q_{D 1}, p, Y(t)\right) \quad p \cdot Q_{D} \leq W_{\max } .
\end{aligned}
$$

In the free market, there is a general equilibrium rule between the supply and demand. The rule can be expressed as

$$
Q_{S}=Q_{D}
$$

Actually, the supply-demand relation is a core of the overall MBC theory. There have been several mathematical models reflecting the supply-demand relation by now, such as linear-supply and linear-demand model [14], linear-supply and power-demand model [16], advanced linear-supply and power-demand model, and linear-supply and exponentialdemand model [16]. Detailed introductions of these supplydemand models can be found in corresponding references. A simple relation of the supply function and price, linear model, is used here as

$$
Q_{S}=\eta \cdot p(t)
$$

And the advanced linear-supply and power-demand model (ALPM) demand function is chosen to depict the relation of the demand and price as

$$
Q_{D}=\frac{W(t)|\alpha x(t)+\beta \dot{x}(t)|}{p(t)},
$$

where $\eta$ is the parameter that reflects the energy supply, $x$ and $\dot{x}$ are the story-displacement and story-velocity of the structural system and $\alpha$ and $\beta$ are the weighting coefficients.

Substituting (4) and (5) into (3), an equilibrium price is obtained through solving (3) at any time step. The distribution of scarce resources reaches maximized benefits under the equilibrium price. The solution of (3) is called the Pareto optimal solution in economics [13]. Then, the control force is written as

$$
U(t)=-K \cdot \frac{W(t) \cdot(\alpha x(t)+\beta \dot{x}(t))}{p(t)},
$$

where $K$ is the gain coefficient related to the actuator.

Substitute (6) into (1); the MBC is implemented in the structural vibration control.

2.2. Experiment. A single-degree-of-freedom of structural model is made of steel and organic glass plates. The organic glass plate is chosen to model the floor of structure, and steel plates are as structural elements for resisting lateral force. Two piezoelectric ceramic thin plates are affixed on the surface of steel plates, one of which named the PZT-1 is an exciting device at the beginning of experiment, and it becomes an actuator to control the structural response after the excitation and another of which named the PZT-2 is a collecting sensor for the structural response. The structural model and piezoelectric ceramic thin plates are shown in Figure 1 and their parameters are listed in Tables 1 and 2.

The model vibrates under the excitation by the PZT- 1 at the beginning and the vibration makes the PZT-2 deformed and results in electric signals change. The response of structural model is obtained from collecting and processing the electric signals. The PZT-1 is an actuator during structural 
TABLE 1: Parameters of the structural model.

\begin{tabular}{|c|c|c|c|c|}
\hline Component & Mass (kg) & Size $(\mathrm{mm})$ & Elastic modulus $(\mathrm{Pa})$ & Number \\
\hline Organic glass & 0.496 & $350 \times 120 \times 10$ & - & 2 \\
\hline Steel & 0.471 & $500 \times 120 \times 1$ & $2.06 \times 10^{11}$ & 2 \\
\hline
\end{tabular}

TABLE 2: Parameters of the piezoelectric.

\begin{tabular}{lccccc}
\hline \multirow{2}{*}{ Piezoelectric ceramic } & Size $(\mathrm{mm})$ & Relative freedom dielectric constant & \multicolumn{3}{c}{ Piezoelectric constant $\left(10^{-12} \mathrm{C} / \mathrm{N}\right)$} \\
\hline PZT-1 & $\varepsilon_{\operatorname{Tr} 3}$ & $\varepsilon_{\operatorname{Tr} 1}$ & $D_{31}$ & $D_{33}$ \\
PZT-2 & $30 \times 40 \times 0.4$ & 1400 & 1550 & 160 & 350 \\
\hline
\end{tabular}

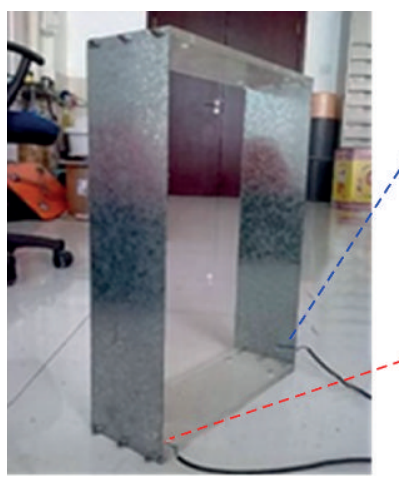

(a) Model

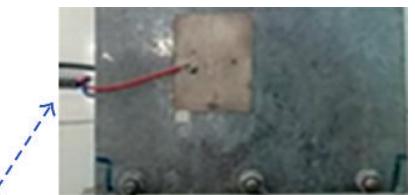

(b) PZT-1

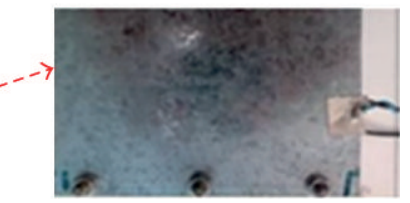

(c) PZT-2
FIGURE 1: Structural model in test.

model vibration. The value of control force from the PZT1 is calculated by the MBC strategy based on the structural response status from the PZT-2. The whole control process is shown in Figure 2.

Experimental devices include a PC with the MBC strategy, input and out control board, and piezoelectric driving device. All these devices are shown in Figures 3, 4, and 5.

The natural vibration frequency of model is $18.1 \mathrm{~Hz}$ through the swept-frequency method. When the frequency of the environmental load equals natural frequency of the model, the vibration response of the structural model reaches maximum value. Thereby, the exciting load is defined as

$$
P(t)=\sin (18.1 t) .
$$

Figures 6 and 7 show proportional acceleration and displacement responses of the structural model, respectively. The proportional acceleration is a signal measured directly from the PZT-2. It can be transferred to an absolute acceleration through multipling a parameter related to the piezoelectric. In this study, the main objective of this experiment is focused on comparing the effectiveness of the MBC. Therefore, the proportional response is used here directly. It can be seen that the response of model controlled by the $\mathrm{MBC}$ has an obvious reduction than that of model with free vibration (FRE).

Figure 8 shows the relation of theoretical control force and time, which is equal to the ratio of actual force to gain coefficient. Figure 9 illustrates that the price has the same

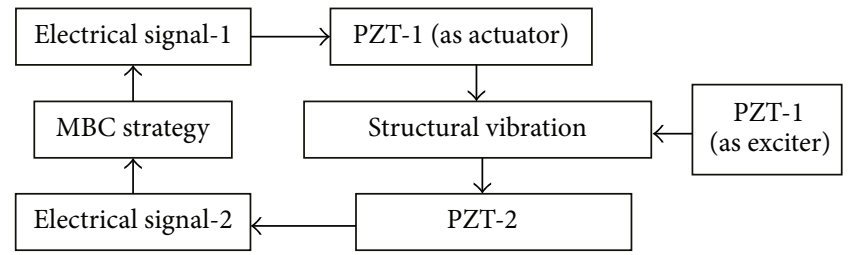

FIGURE 2: Experimental program.

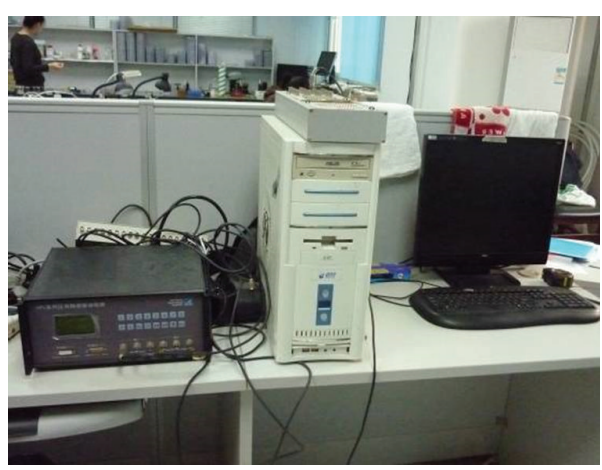

FIgURE 3: Computer of control system.

changing trend as the theoretical control force in time history. The change regularity of price in the market is consistent with that of control force from actuator illustrated efficiency of the MBC algorithm.

\section{Application of the MBC in Long-Span Bridges}

3.1. Governing Equation considering the Multiple Support. The equation of motion for the bridge considering multi-support is written as

$$
\begin{aligned}
{\left[\begin{array}{ll}
\mathbf{M}_{\mathrm{ss}} & \mathbf{M}_{\mathrm{sb}} \\
\mathbf{M}_{\mathrm{bs}} & \mathbf{M}_{\mathrm{bb}}
\end{array}\right]\left\{\begin{array}{l}
\ddot{\mathbf{X}}_{\mathrm{s}} \\
\ddot{\mathbf{X}}_{\mathbf{b}}
\end{array}\right\} } & +\left[\begin{array}{ll}
\mathbf{C}_{\mathrm{ss}} & \mathbf{C}_{\mathrm{sb}} \\
\mathbf{C}_{\mathrm{bs}} & \mathbf{C}_{\mathbf{b b}}
\end{array}\right]\left\{\begin{array}{l}
\dot{\mathbf{X}}_{\mathrm{s}} \\
\dot{\mathbf{X}}_{\mathbf{b}}
\end{array}\right\} \\
& +\left[\begin{array}{ll}
\mathbf{K}_{\mathrm{ss}} & \mathbf{K}_{\mathrm{sb}} \\
\mathbf{K}_{\mathrm{bs}} & \mathbf{K}_{\mathrm{bb}}
\end{array}\right]\left\{\begin{array}{l}
\mathbf{X}_{\mathrm{s}} \\
\mathbf{X}_{\mathbf{b}}
\end{array}\right\}+\left\{\begin{array}{l}
\mathbf{U}_{\mathrm{s}} \\
\mathbf{U}_{\mathbf{b}}
\end{array}\right\}=\left\{\begin{array}{l}
\mathbf{P}_{\mathrm{s}} \\
\mathbf{P}_{\mathbf{b}}
\end{array}\right\},
\end{aligned}
$$




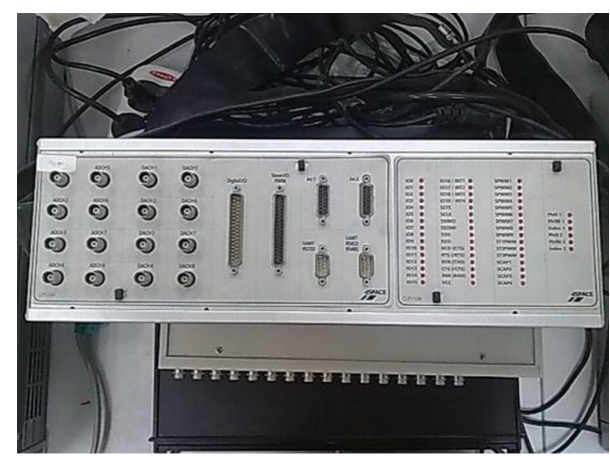

Figure 4: I/O interface board.

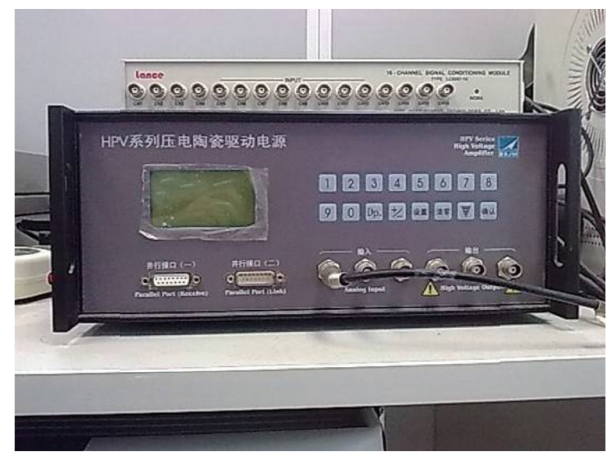

FIgURE 5: Piezoelectric driving power.

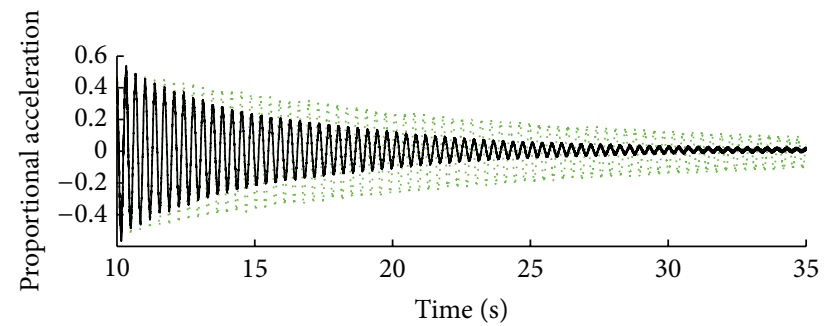

FRE

$-\mathrm{MBC}$

Figure 6: Acceleration time-history response curve.

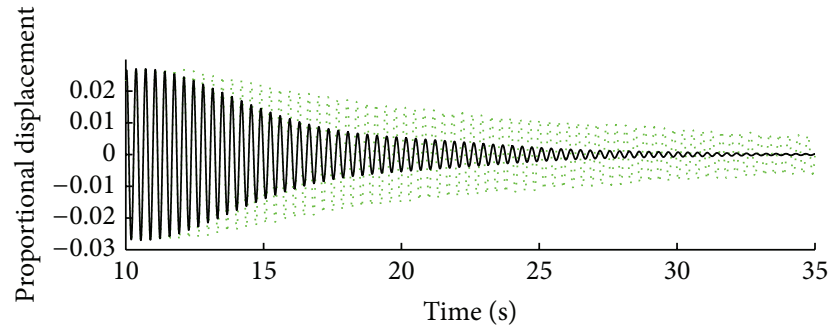

FRE

$-\mathrm{MBC}$

FIGURE 7: Displacement time-history response curve.

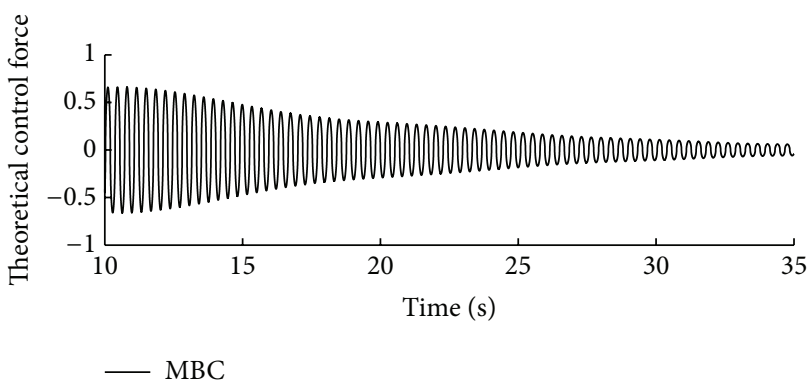

FIGURE 8: Control force time-history response curve.

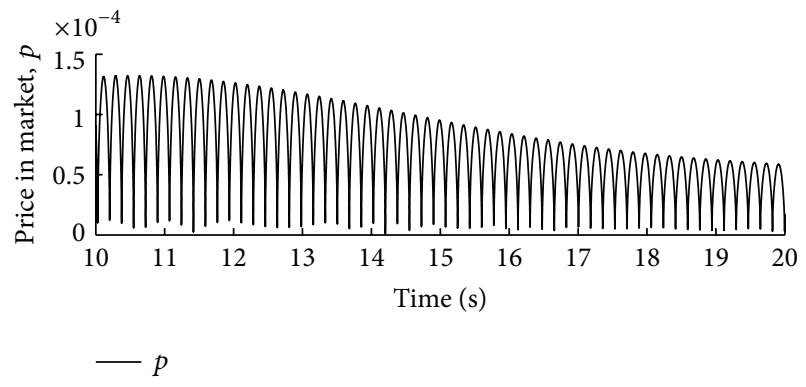

FIGURE 9: Price time-history response curve.

where $\mathbf{M}, \mathbf{C}$, and $\mathbf{K}$ are the mass, damping, and stiffness matrices, respectively; $\mathbf{U}$ and $\mathbf{P}$ are the control force vectors from actuator and environmental force; $\ddot{\mathbf{X}}, \dot{\mathbf{X}}$, and $\mathbf{X}$ are the absolute acceleration, velocity, and displacement response vectors, respectively. Subscripts $\mathbf{s}$ and $\mathbf{b}$ stand for the structure and the support. Equation (8) can be rearranged as

$$
\mathbf{M}_{s s} \ddot{X}_{s}+C_{s s} \dot{X}_{s}+K_{s s} \mathbf{X}_{s}=P_{s}-U_{s}-M_{s b} \ddot{X}_{b}-C_{s b} \dot{X}_{b}-K_{s b} \mathbf{X}_{b} \text {. }
$$

The displacement $\mathbf{X}_{\mathbf{s}}$ is expressed by

$$
\mathbf{X}_{\mathrm{s}}=\mathbf{X}_{\mathrm{ds}}+\mathbf{X}_{\mathrm{ss}}
$$

where $\mathbf{X}_{\mathbf{d s}}$ and $\mathbf{X}_{\mathrm{ss}}$ are the dynamic response and the pseudostatic response. Additionally, for the pseudostatic response of the structure, there is the following relation:

$$
\mathbf{X}_{\mathrm{ss}}=-\mathbf{K}_{\mathrm{ss}} \mathbf{K}_{\mathrm{sb}} \mathbf{X}_{\mathbf{b}}=-\mathbf{R} \mathbf{X}_{\mathbf{b}} \text {, }
$$

where $\mathbf{R}=-\mathbf{K}_{\mathbf{s s}}{ }^{-1} \mathbf{K}_{\mathbf{s b}}$. Substituting (10) and (11) to (9), there is

$$
\begin{aligned}
& \mathbf{M}_{\mathrm{ss}} \ddot{\mathbf{X}}_{\mathrm{ds}}+\mathbf{C}_{\mathrm{ss}} \dot{\mathbf{X}}_{\mathrm{ds}}+\mathbf{K}_{\mathrm{ss}} \mathbf{X}_{\mathrm{ds}} \\
& \quad=\mathbf{P}_{\mathbf{s}}-\mathbf{U}_{\mathrm{s}}-\left(\mathbf{M}_{\mathrm{ss}} \mathbf{R}+\mathbf{M}_{\mathrm{sb}}\right) \ddot{\mathbf{X}}_{\mathrm{b}}-\left(\mathbf{C}_{\mathrm{ss}} \mathbf{R}+\mathbf{C}_{\mathrm{sb}}\right) \dot{\mathbf{X}}_{\mathrm{b}} .
\end{aligned}
$$

The damping item $\left(\mathbf{C}_{\mathbf{s s}} \mathbf{R}+\mathbf{C}_{\mathbf{s b}}\right) \dot{\mathbf{X}}_{\mathbf{b}}$ has little influence on structural responses and can be neglected. Equation (12) is then simplified to

$$
\mathbf{M}_{\mathrm{ss}} \ddot{\mathbf{X}}_{\mathrm{ds}}+\mathrm{C}_{\mathrm{ss}} \dot{\mathbf{X}}_{\mathrm{ds}}+\mathbf{K}_{\mathrm{ss}} \mathbf{X}_{\mathrm{ds}}=\mathbf{P}_{\mathrm{s}}-\mathrm{U}_{\mathrm{s}}-\left(\mathbf{M}_{\mathrm{ss}} \mathbf{R}_{\mathrm{s}}+\mathbf{M}_{\mathrm{sb}}\right) \ddot{\mathbf{X}}_{\mathrm{b}}
$$




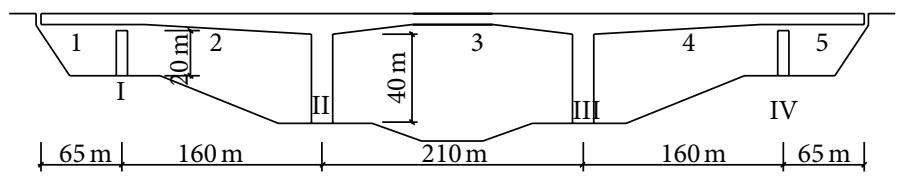

FIGURE 10: Schematic diagram of the long-span bridge.

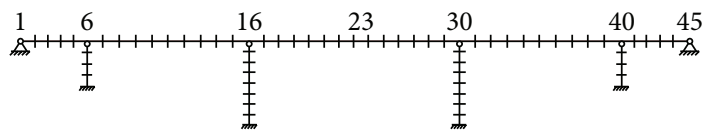

Figure 11: Finite element model of bridge.

TABLE 3: Parameters of MRD.

\begin{tabular}{lccccc}
\hline$D(\mathrm{~mm})$ & $L(\mathrm{~mm})$ & $d(\mathrm{~mm})$ & $h(\mathrm{~mm})$ & $\gamma(\mathrm{Pa} \cdot \mathrm{s})$ & $\tau_{\max }(\mathrm{Pa})$ \\
\hline 250 & 500 & 100 & 2 & 1 & 50 \\
\hline
\end{tabular}

3.2. Supply-Demand Relation Model. In this section, linearsupply and exponent model [16] was used as control function.

The supply function is written as

$$
Q_{S, i}=\eta_{i} \cdot p .
$$

The demand function is expressed by

$$
Q_{D, i}=W_{i}\left|\alpha_{i} x_{d, i}+\beta_{i} \dot{x}_{d, i}\right| \cdot e^{-c p},
$$

where $\eta_{i}$ is the parameter that reflects the energy supply of $i$ th actuator, $\dot{x}$ and $\ddot{x}$ are the relative displacement and velocity at ends of the $i$ th actuator, $\alpha_{i}$ and $\beta_{i}$ are the weighting coefficients, $W_{i}$ is the initial wealth of the $i$ th buyer, and $p_{j}$ is the equivalent price of the $i$ th actuator.

The equilibrium price $p$ is solved through defining (14) and (15) equal. Then, control force of the $i$ th actuator is expressed based on the price as follows:

$$
U_{i}=\eta_{i} \cdot p .
$$

3.3. Numerical Example. A long-span bridge shown in Figure 10 has 660 meters length. Bidirectional sliding bearings are set on the abutments and continuous piers. In order to analyze the control effect of the long-span bridge under the earthquake using the MBC strategy, The Taft earthquake record (July 21, 1951, the acceleration peak value is adjusted to $400 \mathrm{gal}$ ) is selected as an environmental load.

Planar beam elements are used to simulate piers and beams of the bridge. The long-span bridge is modeled with 70 finite elements and 197 freedoms. Figure 11 shows finite element divisions and some typical nodes numbers for convenient expression.

32 Magnetorheological dampers (MRDs) are installed on the abutments, I and IV piers. The modified boundary Hrovat algorithm [21] is used here for numerical simulations. The maximum force from a MRD is $2000 \mathrm{kN}$. Table 3 shows parameters of these MRDs, where $D$ is the cylinder

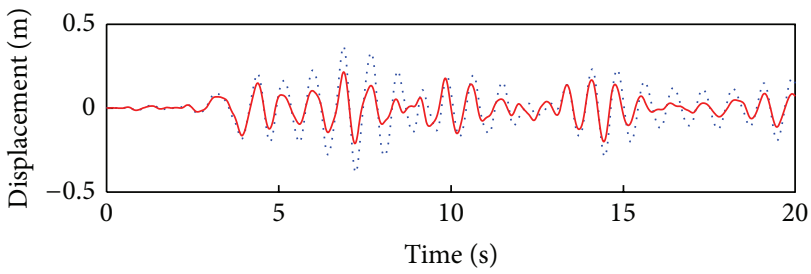

(a)

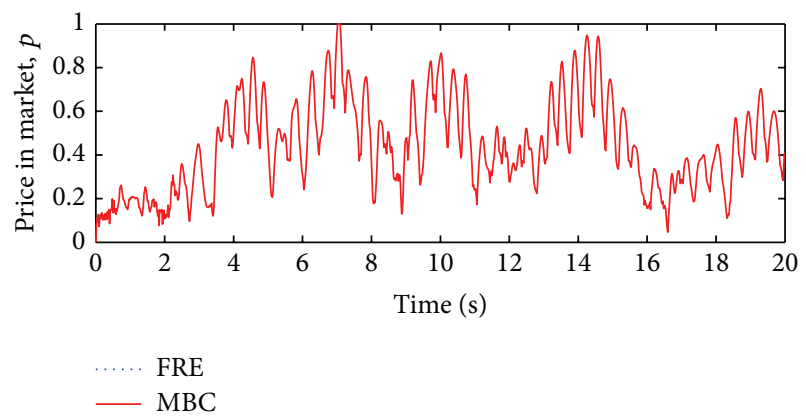

(b)

Figure 12: Displacement and price time history of no. 6 node.

diameter, $L$ is the effective length of the piston, $d$ is the diameter of the piston, $h$ is the gap spacing, $\gamma$ is the apparent viscosity of the liquid, and $\tau_{\max }$ is the maximum yield stress of the liquid.

The traveling wave speed as the known parameter is given during the dynamical time history analysis of the long-span bridge considering multiple supports. In order to find the rule of the response influenced by traveling wave, the velocities of traveling wave $v_{a}$ are set at $400 \mathrm{~ms}^{-1}, 1000 \mathrm{~ms}^{-1}, 3000 \mathrm{~ms}^{-1}$, and infinity.

Figure 12 shows the price and displacement time history of the no. 6 node with the travelling wave speed at $3000 \mathrm{~ms}^{-1}$. It can be seen from these figures that (a) the MBC strategy reduces displacement responses; (b) the displacement changing trend is consistent with the price response in whole time phase. The phenomena of the energy demand increasing by the displacement and velocity are also inflected from (4). It also means that the energy supply also increases by the displacement because of energy demand equaling to energy supply. In addition, it can be drawn from (6) that energy supply is proportional to the equivalent price. Therefore, both the displacement and equivalent price have the same changing trend.

Figures 13 and 14 indicate that forces of MRDs are dependent on not only the displacement but also velocity. 
In order to validate the effectiveness of the MBC with various travelling wave speed, the reduction rate is defined as

$$
\gamma=\frac{x_{0}-x}{x_{0}} \times 100 \%
$$

where $x_{0}$ and $x$ are responses of the bridge without and with actuators, respectively.

Figures 15 and 16 illustrate maximum displacement and acceleration comparisons of typical nodes with various traveling wave speeds. It is found that there are significantly differences of the responses of bridge among these travelling wave speeds. For the bridge without control, the displacement and acceleration responses at these nodes grow with the increase of travelling waves speeds. The greater the travelling wave speed is, the larger the reduction rate becomes. Therefore, effectiveness of the structural control using the MBC without considering the travelling wave effect is superior to that with consideration.

\section{Application of the MBC in Large Space Structures}

4.1. Basic Theory. A free market, which is a large unity, usually consists of many submarkets. The equilibrium price of commodity in each submarket is formed depending on its own supply-demand relation. However, the price tendency of each submarket is toward the whole equilibrium price. Thus, the price of whole market is a dynamic "cobweb" model, and price of each submarket has more or less influence on the price of the whole market. This theory based on multiple submarkets is called the multiple market-based control (MMBC). The advantage of MMBC can realize the decentralized vibration control in the structural control area through the similarity between the submarket and substructure. In each substructure, the controlling force only depends on its own supply-demand relation. Only the supply and demand functions for the MMBC are introduced here, because the framework of MMBC is similar to that of the MBC.

The supply function of the $k$ th seller in the $j$ th submarket is expressed by

$$
Q_{S, k, j}=\eta_{k, j} p_{j}
$$

The demand function of the $i$ th buyer in the $j$ th submarket can be written as

$$
Q_{D, i, j}=\frac{W_{i, j} c_{i, j}\left|\alpha_{i, j} x_{d, i, j}+\beta_{i, j} \dot{x}_{d, i, j}\right|}{p_{j}},
$$

where $x_{d, i, j}$ and $\dot{x}_{d, i, j}$ are relative displacement and velocity of the $i$ th seller in the $j$ th substructure, respectively; $W_{i, j}, c_{j}$, $\alpha_{i, j}$, and $\beta_{i, j}$ are the initial wealth, demand coefficient, and weighting coefficients of the $i$ th buyer in the $j$ th submarket; $p_{j}$ is the price in the $j$ th submarket; $\eta_{k, j}$ is the parameter that reflects the $k$ th seller in the $j$ th submarket.

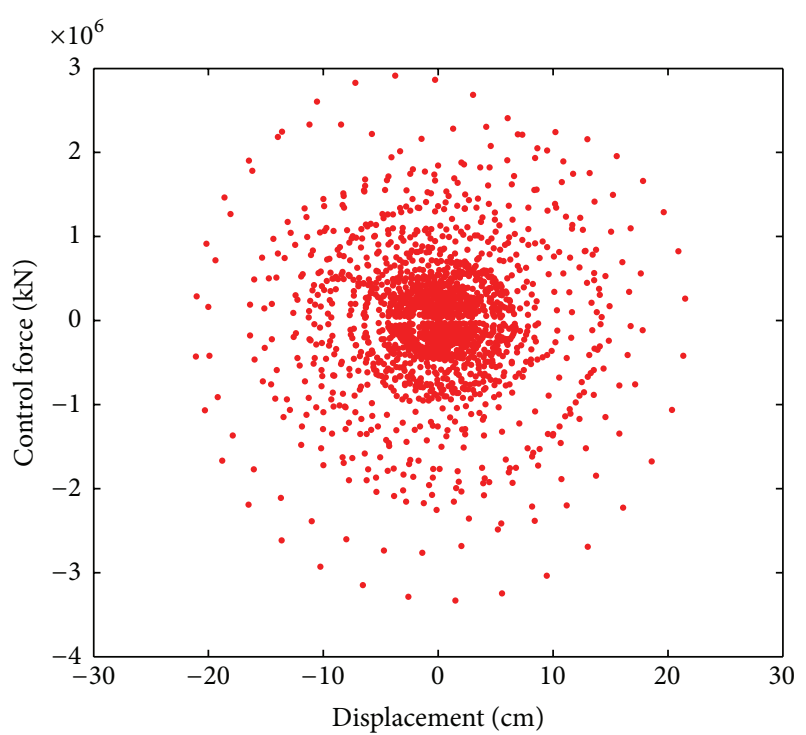

FIGURE 13: Control force versus displacement.

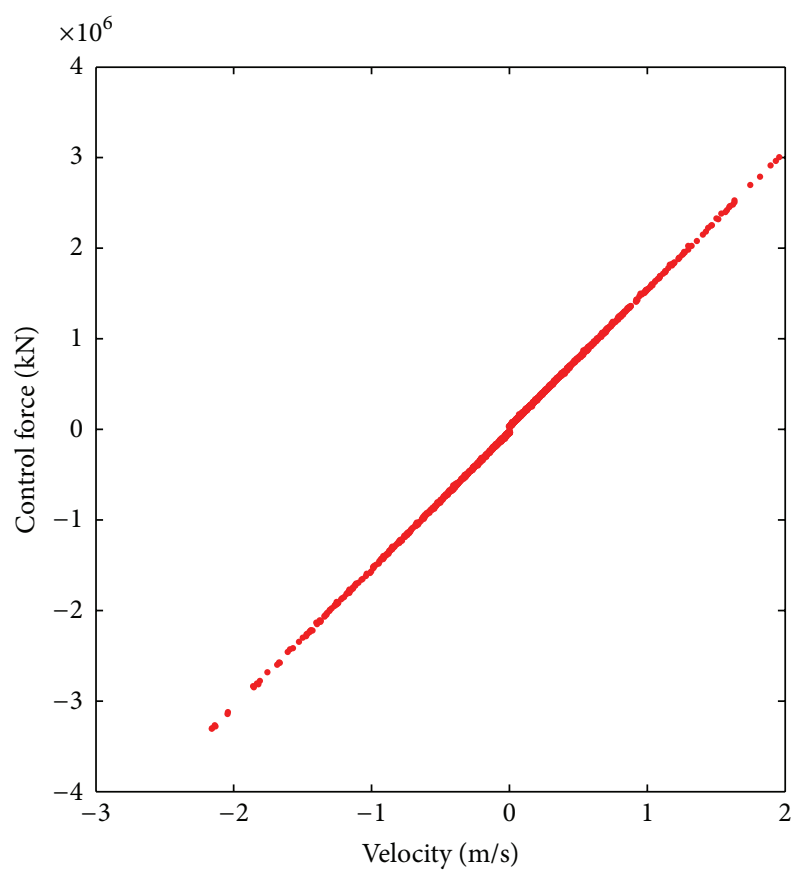

FIGURE 14: Control force versus velocity.

Then, supply-demand relationship of whole market can be written as

$$
\sum_{j=1}^{w} \sum_{i=1}^{r} Q_{D, i, j}=\sum_{j=1}^{w} \sum_{k=1}^{n} Q_{S, k, j}
$$

where $r$ is the number of the actuators, $n$ is the number of energy demand sources, and $w$ is the number of submarkets. The equilibrium price $p_{j}$ is solved from (20) through iterations. The controlling force $U_{i}$ is proportional to the energy 


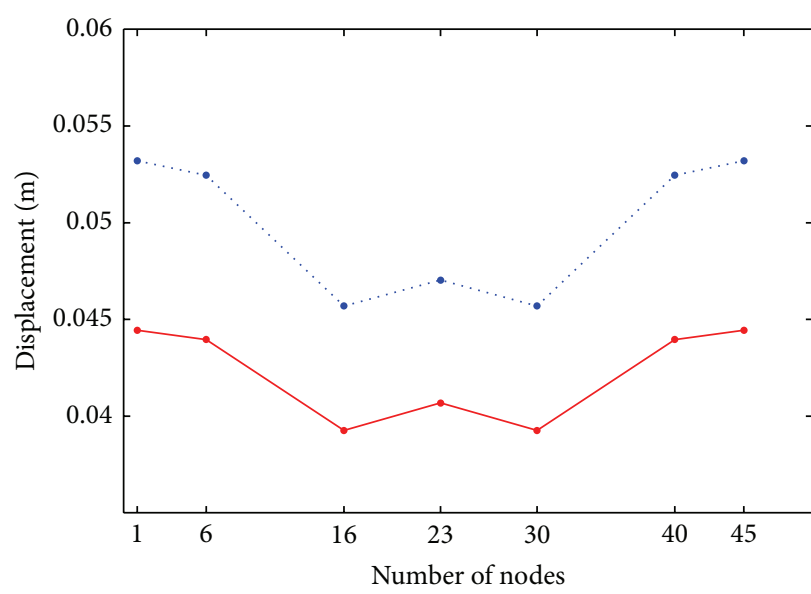

(a) $v_{a}=600 \mathrm{~ms}^{-1}$

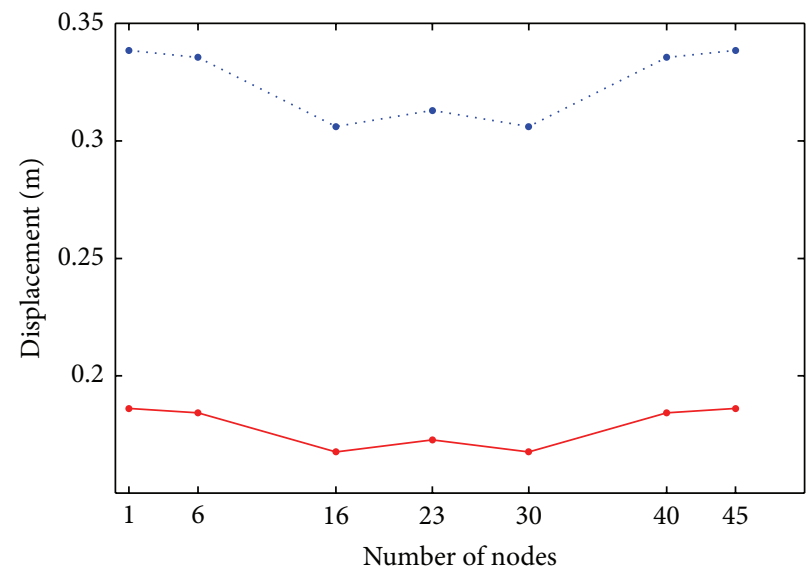

... FRE

- MBC

(c) $v_{a}=300 \mathrm{~ms}^{-1}$

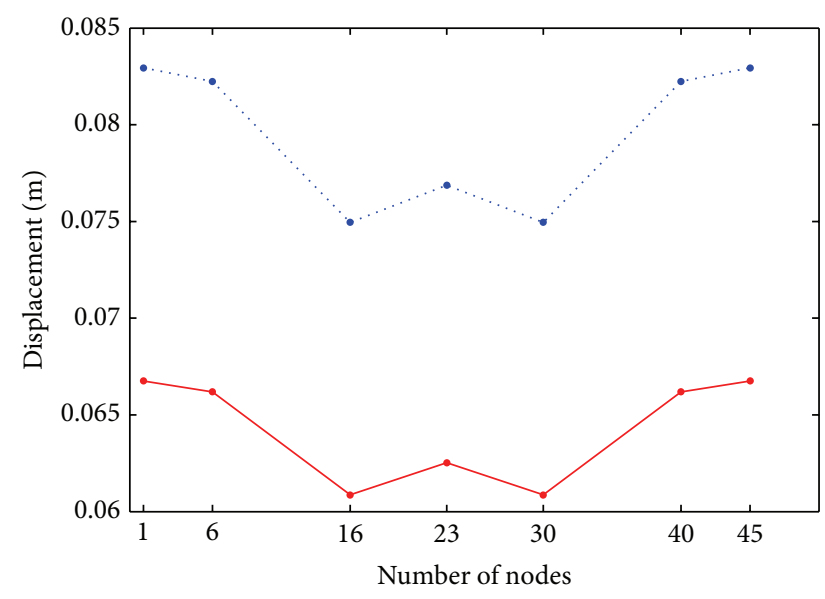

(b) $v_{a}=100 \mathrm{~ms}^{-1}$

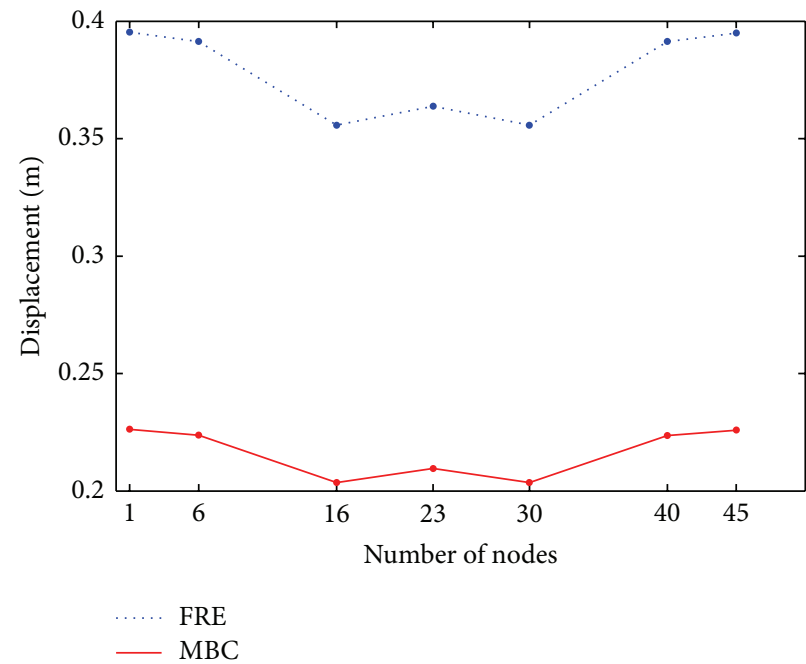

(d) Consistent excitation $\left(v_{a}=\right.$ inf)

FIGURE 15: Displacement response with and without control at various velocities of travelling waves.

supply at the price $p_{j}$. The force from actuator can be drawn as

$$
U_{i}=-K_{i, j} \frac{W_{i, j} c_{i, j}\left|\alpha_{i, j} x_{d, i, j}+\beta_{i, j} \dot{x}_{d, i, j}\right|}{p_{j}}
$$

where $K_{i, j}$ means the gain coefficient of controlling force from the $i$ th actuator of $j$ th substructure. Substituting (21) into the structure dynamic equation, application of the MMBC to structure may be realized.

4.2. Numerical Example. A reticulated shell structure (RSS) with $40 \mathrm{~m}$ span, $8 \mathrm{~m}$ high and 5 span-height ratio is shown in Figure 17. It has four support positions at node Number 127, 140, 151, and 163. The RSS consists of two kinds of circular $4 \mathrm{~mm}$ thick steel tubes: one is $133 \mathrm{~mm}$ in diameter; another is $140 \mathrm{~mm}$ in diameter. The first one is used for string bar elements of RSS and the second is adopted for support bars. In order to validate the effectiveness of MMBC for the largespace structure in three dimensions, a 3-dimensional finite element model is established and the El Centro earthquake record (NS, May 18, 1940, the acceleration peak value is adjusted to $400 \mathrm{gal}$ ) is inputted in the RSS along $X, Y$, and $Z$ directions. The MRDs are installed at node Number 133, 145, 157, and 169 shown in Figure 17. There are three MRDs, each is aligned with $X, Y$, and $Z$ directions at each nodal position. The RSS is distributed into three substructures named as the substructure- $X$, substructure- $Y$, and substructure- $Z$ for the MMBC strategy application.

Figures 18 and 19 illustrate displacement and acceleration time history responses of the RSS with and without control. Tables 4 and 5 show the maximum response and reduction rate of typical nodes. It is obviously found from the above figures and tables that the displacement response can be controlled effectively, especially on the displacement in $Z$ direction. However, the effectiveness of the acceleration controlling is limited. The reason is that the deformation of the RSS in $Z$ direction is larger than that in $X$ and $Y$ directions, and the acceleration response is not sensitive to such flexible RSS. 


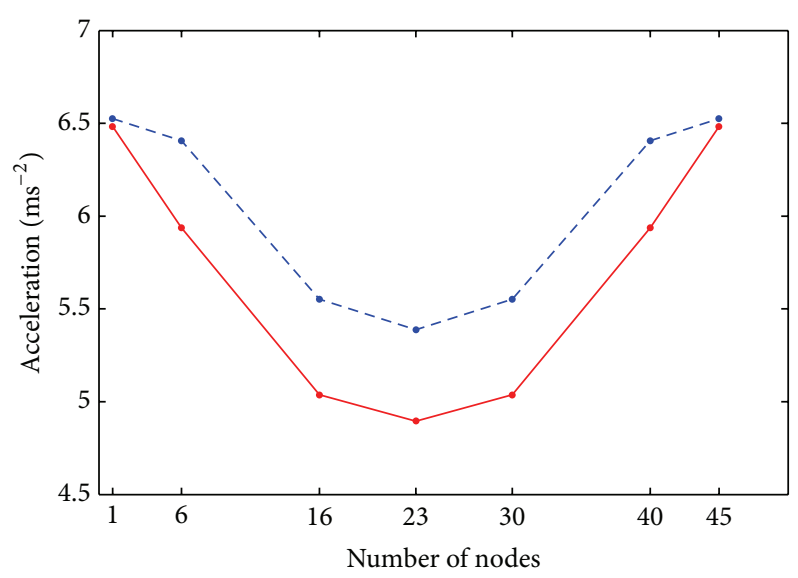

(a) $v_{a}=600 \mathrm{~ms}^{-1}$

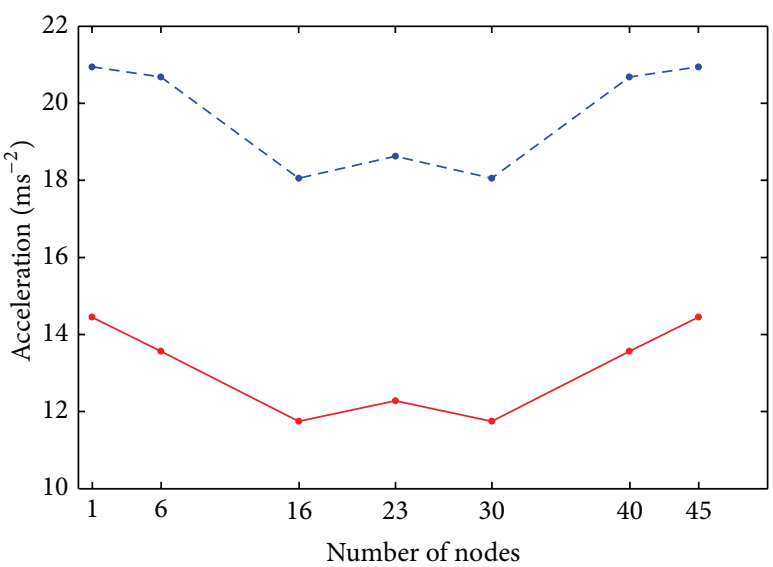

- - FRE

MBC

(c) $v_{a}=3000 \mathrm{~ms}^{-1}$

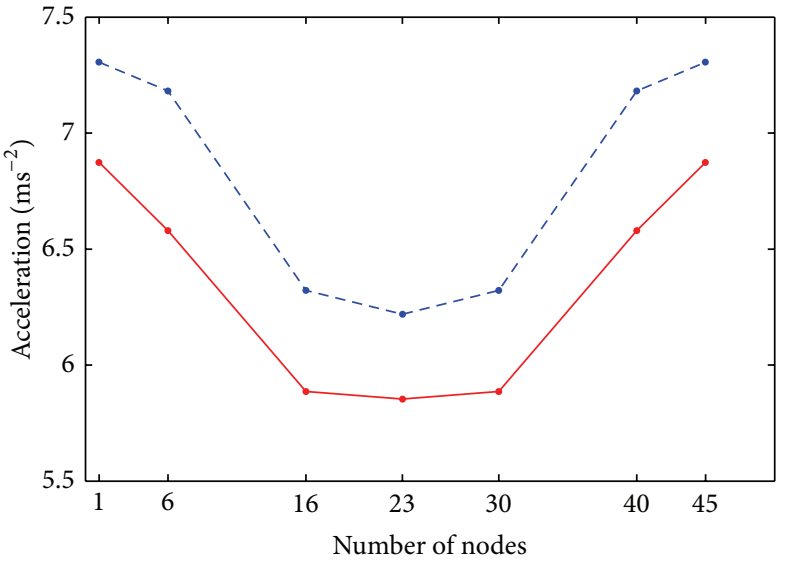

(b) $v_{a}=100 \mathrm{~ms}^{-1}$

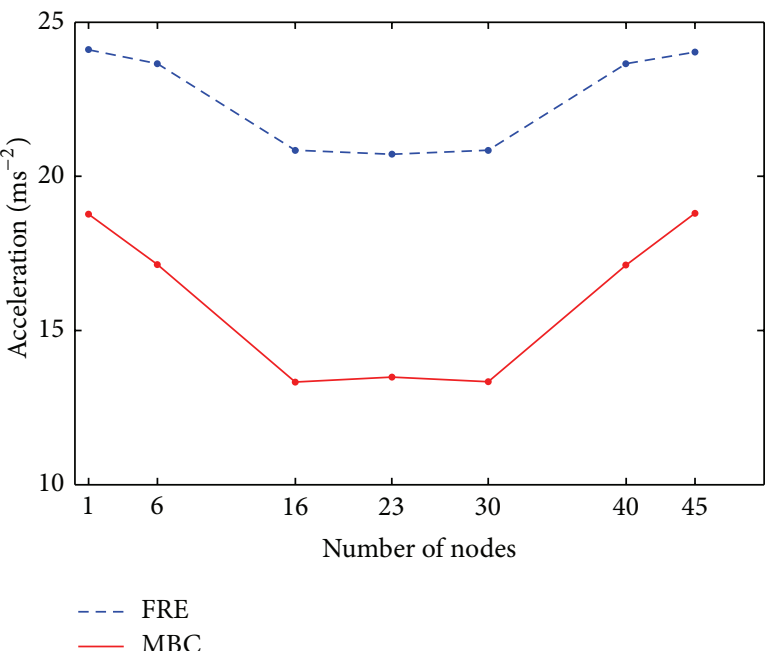

(d) Consistent excitation $\left(v_{a}=\right.$ inf $)$

FIGURE 16: Acceleration response with and without control at various velocities of travelling waves.

TABLE 4: Maximum displacement response and reduction of typical nodes.

\begin{tabular}{|c|c|c|c|c|c|c|}
\hline \multirow{2}{*}{ Nodes } & \multicolumn{3}{|c|}{ Displacement (mm) } & \multicolumn{3}{|c|}{ Reduction $\gamma_{d}(\%)$} \\
\hline & $X$ & Y & $Z$ & $X$ & $Y$ & $Z$ \\
\hline 1 & $2.16 / 1.88$ & $1.53 / 1.28$ & $5.50 / 3.72$ & 12.9 & 15.9 & 32.3 \\
\hline 9 & $2.14 / 1.86$ & $1.41 / 1.19$ & $5.94 / 4.15$ & 12.9 & 15.8 & 30.1 \\
\hline 25 & $2.01 / 1.77$ & $1.22 / 1.04$ & $7.68 / 5.91$ & 12.1 & 15.2 & 23.1 \\
\hline 27 & $2.03 / 1.86$ & $1.45 / 1.19$ & $5.67 / 4.42$ & 8.8 & 18.3 & 22.1 \\
\hline 52 & $2.98 / 2.36$ & $2.26 / 1.84$ & $4.26 / 3.67$ & 20.9 & 18.5 & 13.9 \\
\hline 85 & $4.39 / 3.74$ & $4.95 / 3.71$ & $7.59 / 7.11$ & 14.8 & 25.1 & 6.4 \\
\hline 127 & $6.61 / 6.07$ & $6.36 / 5.96$ & $10.3 / 9.53$ & 8.2 & 6.4 & 7.7 \\
\hline
\end{tabular}

Figures 20 and 21 show the price and control force time history of three various substructures. Since the price $p$ is a function of supply-demand model and responses of the RSS, it varies from different submarkets. In addition, the same regularity and changing trend between displacement and price in each substructure also is observed from these figures.

\section{Concluding Remarks}

In this paper, a vibration control experiment is carried out to validate the MBC effectiveness. The MBC is then applied to a long-span bridge considering the travelling wave effect. On the basis of MBC theory, the MMBC is presented here and applied to a large-space structure, taking into account 


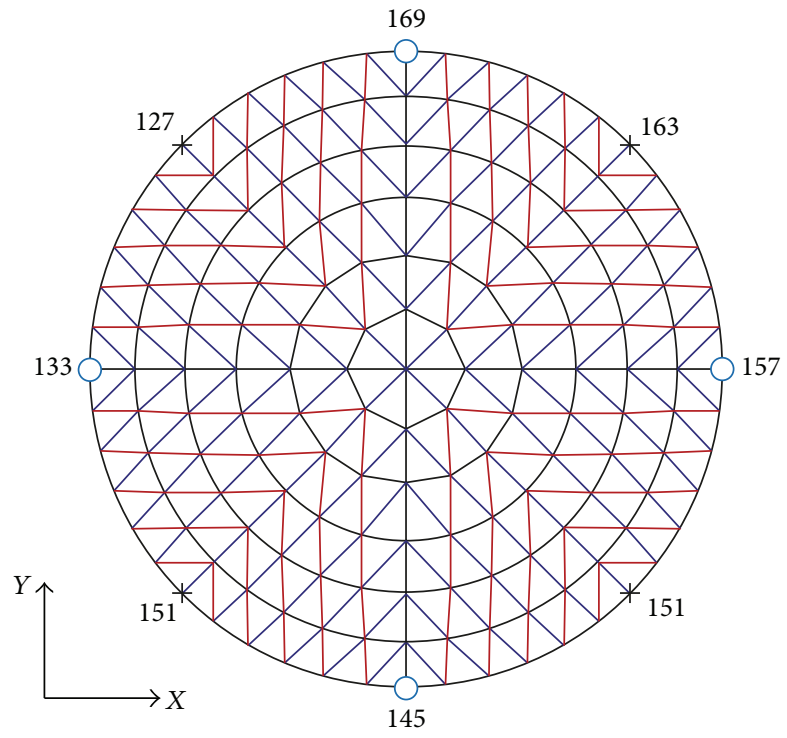

(a)

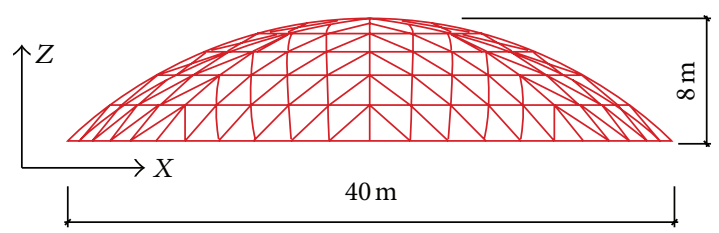

(b)

FIGURE 17: Reticulated shell structure model.

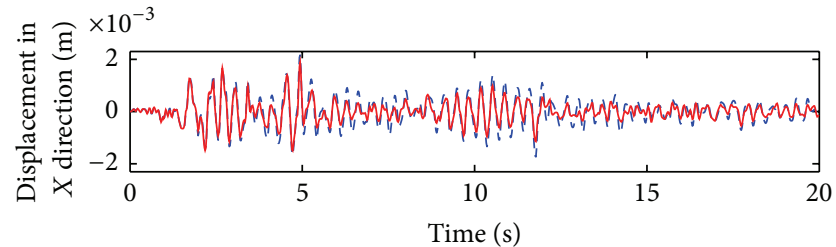

Time (s)

- - FRE

- MBC

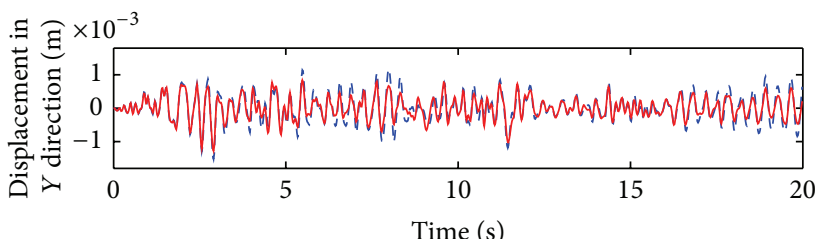

- - FRE

- MBC

(a)

(b)

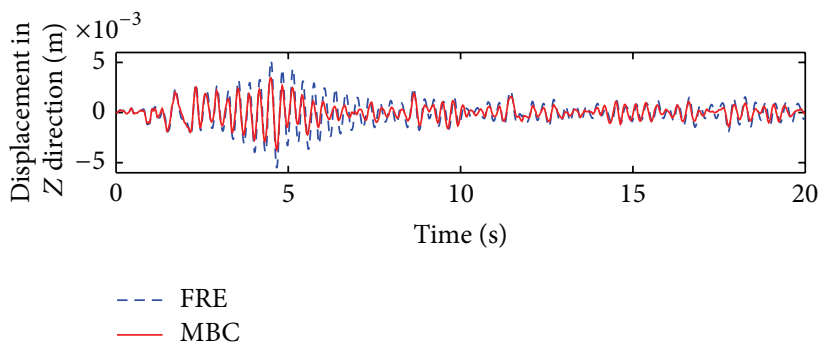

(c)

FIGURE 18: Displacement time history.

TABLE 5: Maximum acceleration response and reduction of typical nodes.

\begin{tabular}{|c|c|c|c|c|c|c|}
\hline \multirow{2}{*}{ Nodes } & \multicolumn{3}{|c|}{ Displacement $\left(\mathrm{ms}^{-2}\right)$} & \multicolumn{3}{|c|}{ Reduction $\gamma_{a}(\%)$} \\
\hline & $X$ & Y & $Z$ & $X$ & $Y$ & $Z$ \\
\hline 1 & $4.95 / 4.90$ & $5.19 / 5.21$ & $4.56 / 4.38$ & 0.9 & -0.3 & 3.9 \\
\hline 9 & $4.99 / 4.30$ & $5.23 / 5.26$ & $5.09 / 4.89$ & 1.1 & -0.4 & 3.8 \\
\hline 25 & $5.11 / 5.06$ & $5.17 / 5.18$ & $5.95 / 5.71$ & 1.1 & -0.3 & 4.0 \\
\hline 27 & $5.29 / 5.23$ & $5.09 / 5.11$ & $5.03 / 4.84$ & 1.0 & -0.2 & 3.6 \\
\hline 52 & $5.46 / 5.46$ & $4.95 / 4.90$ & $5.65 / 5.56$ & 0.0 & 0.9 & 1.5 \\
\hline 85 & $5.26 / 5.20$ & $4.92 / 4.97$ & $9.42 / 6.97$ & 1.2 & -1.1 & 4.8 \\
\hline 127 & $6.31 / 5.86$ & $7.08 / 6.61$ & $10.2 / 9.32$ & 7.1 & 6.6 & 8.3 \\
\hline
\end{tabular}




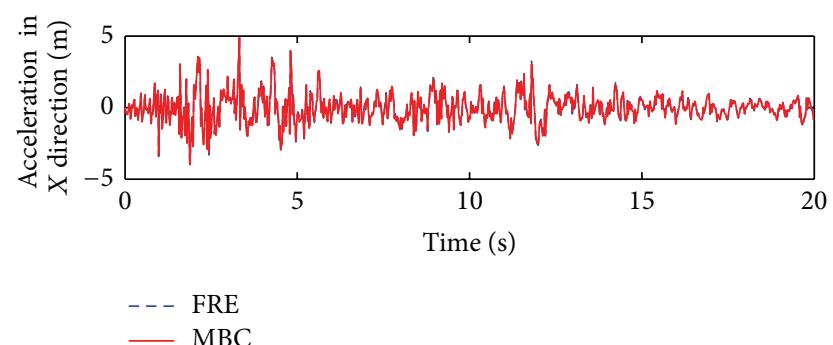

(a)

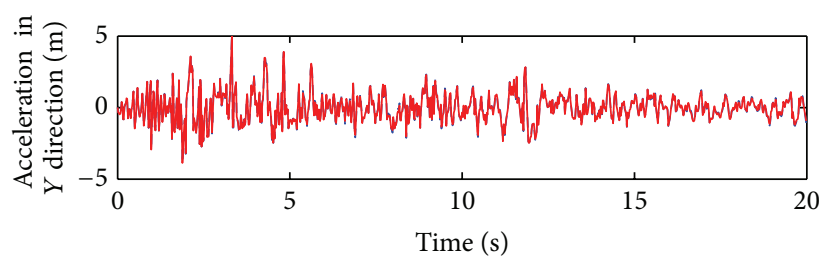

- - FRE

- MBC

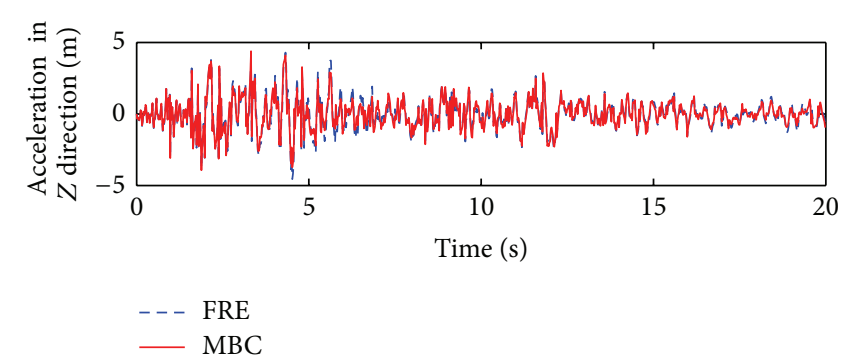

(b)

(c)

Figure 19: Acceleration time history.

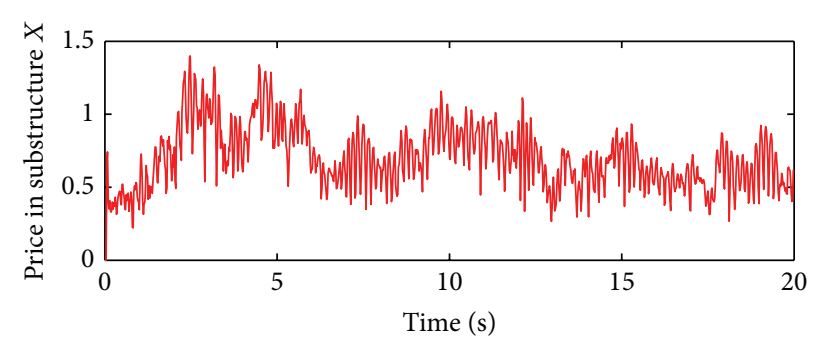

(a)

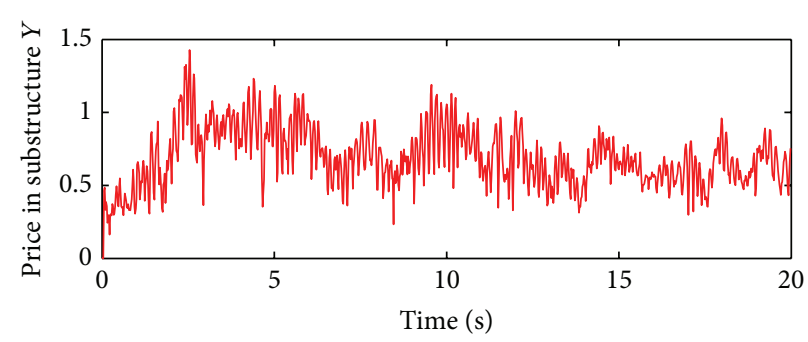

(b)

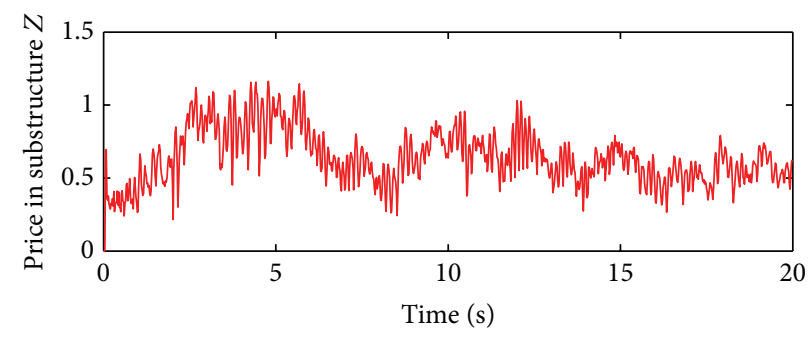

(c)

FIGURE 20: Price time history of substructure.

the multiple dimensions of ground motions. The following conclusions are drawn in this study.

(1) The experiment validates that the MBC is an effective control strategy offering significant controlling force and value to be applied in actual structures.

(2) The travelling wave effect has a distinct influence on responses of the long-span bridge. The MBC strategy can reduce displacement and acceleration responses of the bridge both with and without the travelling wave effects. The greater the velocity of travelling wave of ground motion is, the larger the response of bridge is and the better the control effect is. Therefore, it is necessary to take the travelling wave effect into consideration during the analysis of vibration control of long-span structure using the MBC.

(3) As the large-space structure is commonly flexible, especially in the vertical direction, the multiple dimensional responses and control effect of this kind of structure have to be considered. Numerical results have indicated that the displacement response of the large-space structure in the vertical direction are usually larger than those in horizontal directions, and 


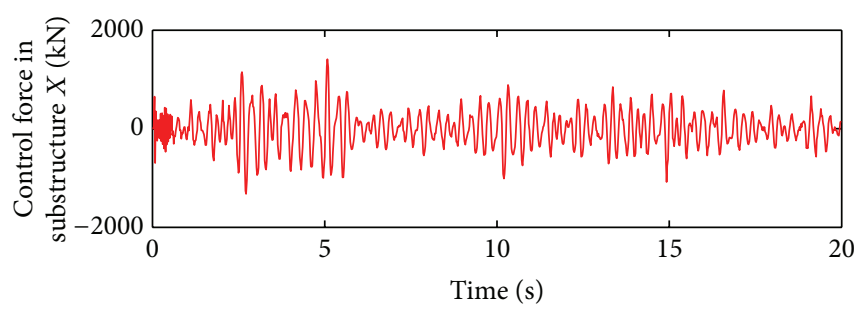

(a)

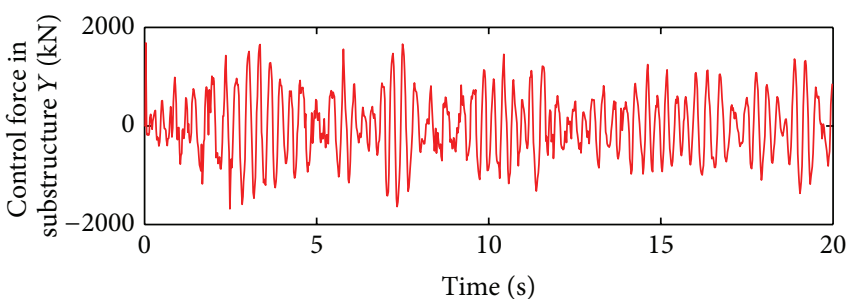

(b)

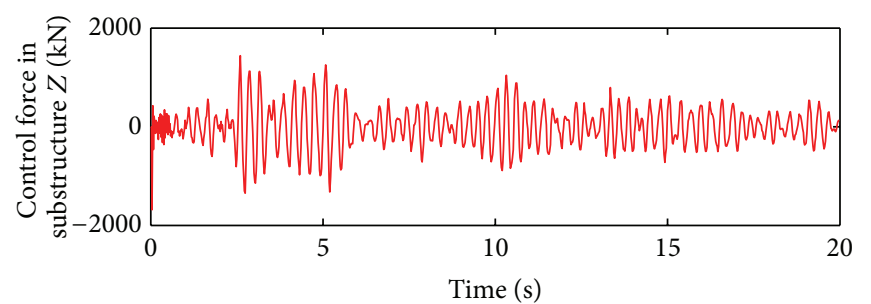

(c)

FIGURE 21: Control force time history of substructures.

the MMBC has better control effect on the displacement response than the acceleration response.

\section{Conflict of Interests}

The authors declare that there is no conflict of interests regarding the publication of this paper.

\section{Acknowledgments}

This research work was jointly supported by the Natural Science Foundation of China (Grants no. 50808036, 91215302) and the Science Fund for Creative Research Groups of the National Natural Science Foundation of China (Grant no. 51121005).

\section{References}

[1] J. T. P. Yao, "Concept of structural control," ASCE Journal of the Structural Division, vol. 98, no. 7, pp. 1567-1574, 1972.

[2] T. T. Soong, Active Structure Control Theory and Practice, Longman Scientific \& Technical, New York, NY, USA, 1990.

[3] J. N. Yang, J. C. Wu, and A. K. Agrawal, "Sliding Model control for nonlinear and hysterestic structures," ASCE Journal of Engineering Mechanics, vol. 121, no. 12, pp. 1330-1339, 1995.

[4] L. Huo, G. Song, H. Li, and K. Grigoriadis, " $\mathrm{H}_{\infty}$ robust control design of active structural vibration suppression using an active mass damper," Smart Materials and Structures, vol. 17, no. 1, Article ID 015021, pp. 15-21, 2008.

[5] A. S. Ahlawat and A. Ramaswamy, "Multiobjective optimal structural vibration control using fuzzy logic control system," ASCE Journal of Structural Engineering, vol. 127, no. 11, pp. 13301337, 2001.

[6] S. Clearwater, Market-Based Control: A Paradigm for Distributed Resource Allocation, World Scientific Publishing, Singapore, 1996.
[7] H. Voos, "Market-based algorithms for optimal decentralized control of complex dynamic systems," in Proceedings of the 38th IEEE Conference on Decision and Control (CDC '99), pp. 32953296, Phoenix, Ariz, USA, December 1999.

[8] W. B. Jackson, C. Mochon, S. K. Van et al., "Distributed allocation using analog market wire computation and communication," in Proceedings of the 7th Mechatronics Forum International Conference, Atlanta, Ga, USA, September 2000.

[9] K. Prouskas, A. Patel, J. Pitt, and J. Barria, "A multi-agent for intelligent network load control using a market-based approach," in Proceedings of the 4th International Conference on Multi-Agent Systems (ICMAS '00), pp. 231-238, IEEE Computer Society, Boston, Mass, USA, July 2000.

[10] T. Alpcan, T. Başar, R. Srikant, and E. Altman, "CDMA uplink power control as a noncooperative game," in Proceedings of the 40th IEEE Conference on Decision and Control (CDC '01), pp. 197-202, Orlando, Fla, USA, December 2001.

[11] J. E. Hilland, R. R. Wessen, D. Porter, and R. S. Austin, "A market-based conflict resolution approach for satellite mission planning," IEEE Transactions on Engineering Management, vol. 48, no. 3, pp. 272-281, 2001.

[12] M. Bernardine and A. Stents, "Comparative study between centralized, market-based, and behavioral multi-robot coordination," in Proceedings of the 2003 IEEE/RSL International Conference on Intelligent Robots and Systems, pp. 2297-2303, Las Vegas, Nev, USA, October 2003.

[13] J. P. Lynch and K. H. Law, "Market-based control of linear structural systems," Earthquake Engineering and Structural Dynamics, vol. 31, no. 10, pp. 1855-1877, 2002.

[14] J. P. Lynch and K. H. Law, "Energy market-based control of linear civil structures," in Proceedings of the US-Korea Workshop on Smart Structural Systems, Pusan, Korea, 2002.

[15] L. Huo and H. Li, "Control law for market-based semi-active timed liquid column dampers," Chinese Journal of Applied Mechanics, vol. 22, no. 1, pp. 71-75, 2005.

[16] Y. Li, Structural vibration control using MBC strategy [M.S. thesis], Dalian University of Technology, 2007. 
[17] G. Li, Q. Liu, and H. Li, "Inelastic structural control based on MBC and FAM," Mathematical Problems in Engineering, vol. 2011, Article ID 460731, 18 pages, 2011.

[18] H. J. Jung, B. F. Spencer Jr., and I. W. Lee, "Control of seismically excited cable-stayed bridge employing magnetorheological fluid dampers," ASCE Journal of Structural Engineering, vol. 129, no. 7, pp. 873-883, 2003.

[19] M. D. Symans and S. W. Kelly, "Fuzzy logic control of bridge structures using intelligent semi-active seismic isolation systems," Earthquake Engineering \& Structural Dynamics, vol. 28, no. 1, pp. 37-60, 1999.

[20] S. J. Moon, L. A. Bergman, and P. G. Voulgaris, "Sliding mode control of cable-stayed bridge subjected to seismic excitation," Journal of Engineering Mechanics, vol. 129, no. 1, pp. 71-78, 2003.

[21] J. P. Ou, Structural Vibration Control-Active, Semi-Active and Smart Control, Science Press, Beijing, China, 2003.

[22] S. M. Allam and T. K. Datta, "Seismic behaviour of cable-stayed bridges under multi-component random ground motion," Engineering Structures, vol. 21, no. 1, pp. 62-74, 1999.

[23] K. Soyluk, "Comparison of random vibration methods for multi-support seismic excitation analysis of long-span bridges," Engineering Structures, vol. 26, no. 11, pp. 1573-1583, 2004. 


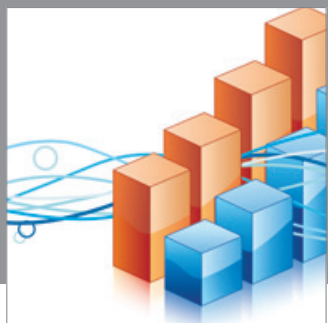

Advances in

Operations Research

mansans

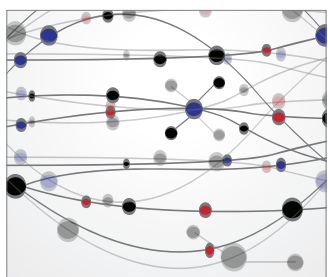

The Scientific World Journal
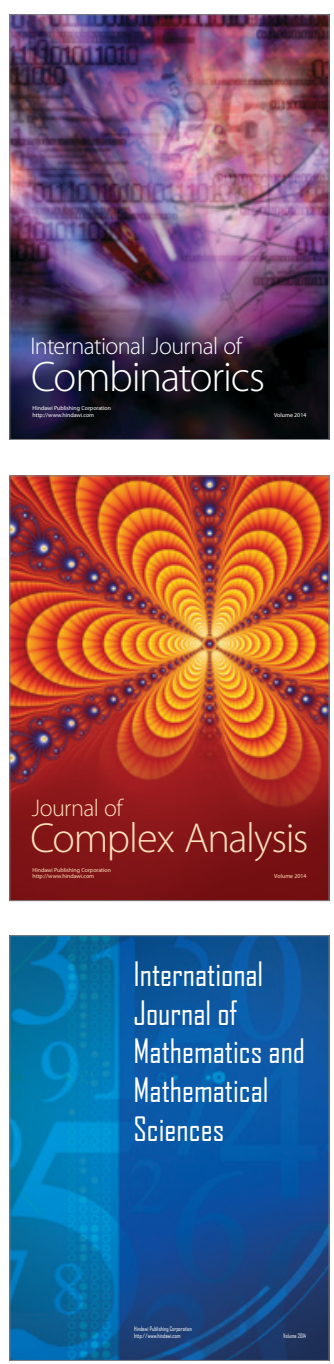
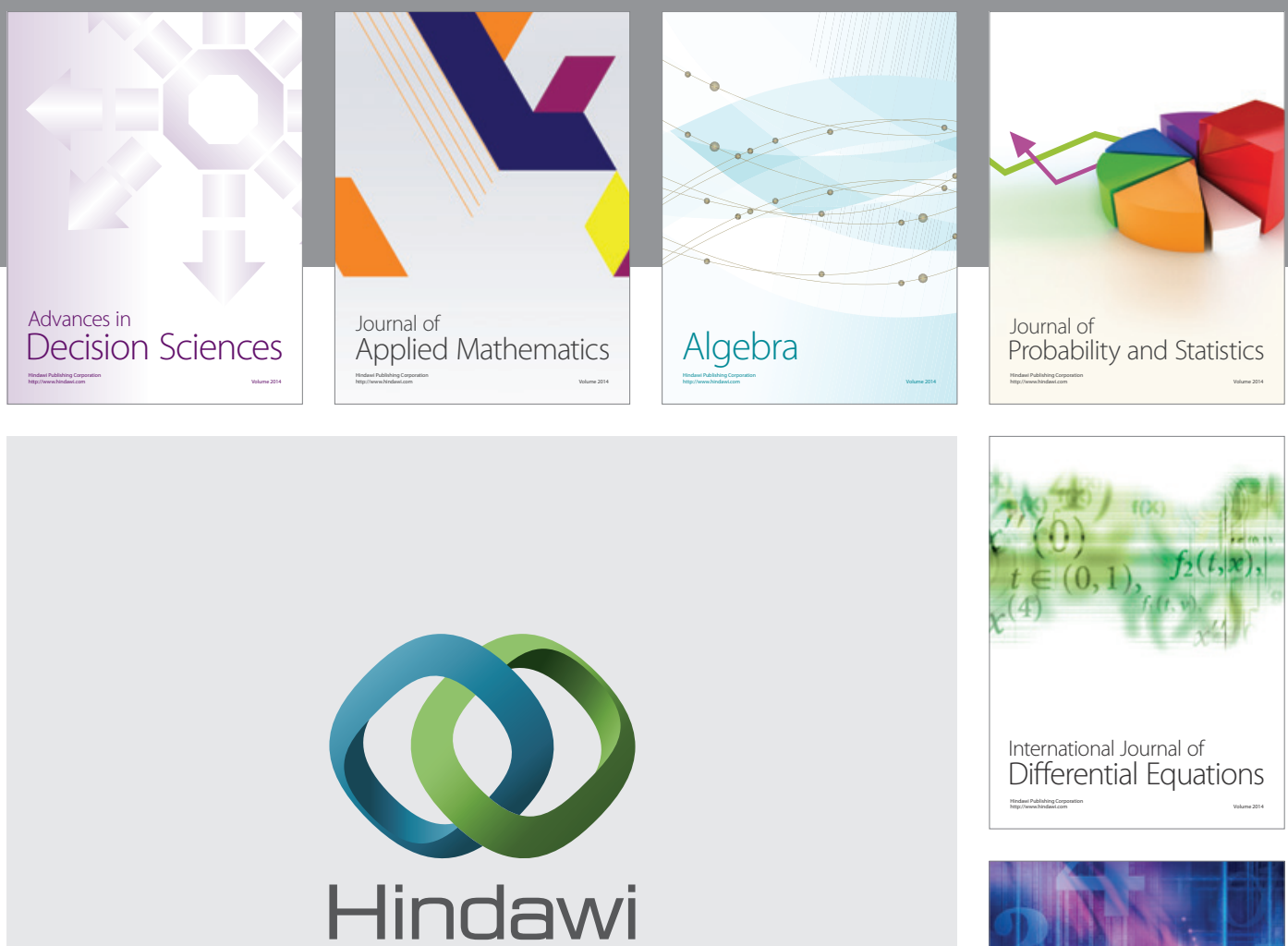

Submit your manuscripts at http://www.hindawi.com
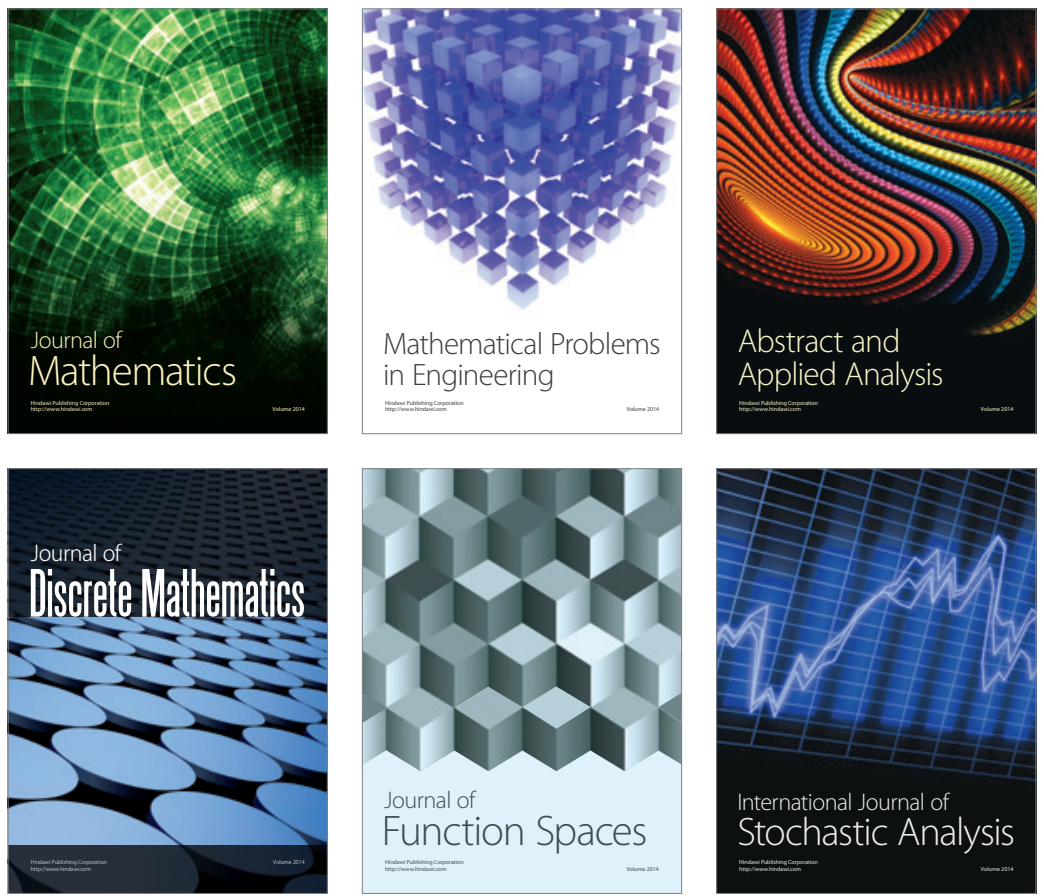

Journal of

Function Spaces

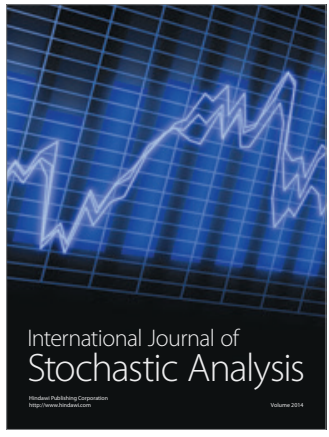

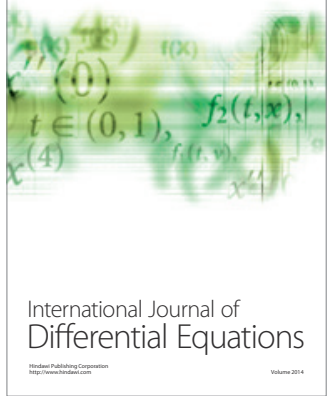
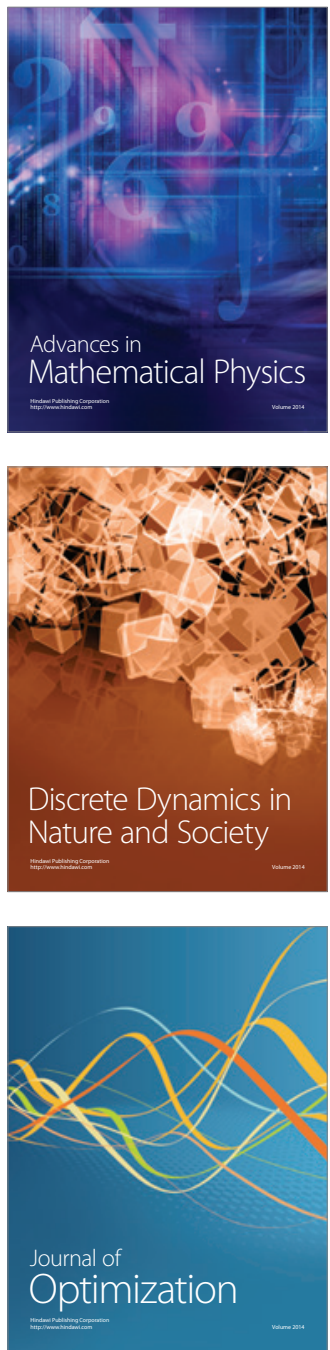